\title{
Capsule Commentary on O'Malley et al., Overcoming Challenges to Teamwork in Patient-Centered Medical Homes: A Qualitative Study
}

\author{
Ming Tai-Seale, $\mathrm{PhD}, \mathrm{MPH}$ \\ Sutter Health Palo Alto Medical Foundation Research Institute, Palo Alto, CA, USA.
}

J Gen Intern Med 30(2):239

DOI: $10.1007 / \mathrm{s} 11606-014-3128-\mathrm{y}$

(c) Society of General Internal Medicine 2014

$\mathrm{H}$ ow do NCQA-recognized patient-centered medical homes (PCMHs) develop and overcome challenges to sustain team-based care?

This question is being raised across the country as medical practices increasingly strive to practice team care, whether to meet NCQA PCMH recognition requirements or to carry out their own strategic directives. While many researchers enumerate the challenges of implementing team care, few offer practical solutions to overcoming them. O'Malley and colleagues' timely paper ${ }^{1}$ is based on $63 \mathrm{key}$ informant interviews at 27 primary care practices that have been recognized by NCQA as level II or level III PCMHs. They offer an impressive number of insights on how these more advanced PCMHs developed teams and overcame challenges.

In addition to the key findings of the study, the paper contains some very intriguing facts. All but one of the 27 practices worked in predominantly fee-for-service arrangements. Furthermore, 20 of them had 10 or fewer physicians. If these findings emerged from across $\mathrm{s}$ spectrum of practice sizes, they suggest that even FFS and relatively small practices can develop and sustain team care, despite the fact that most team members who are not physicians do not directly generate revenue for the practice. It is unclear from the paper, however, whether the success stories were concentrated in larger practices and/or those owned by hospitals or health systems, which may have afforded them more resources. Lastly, most practices used their PCMH funding to hire a part-time care manager. This suggests that such funds have facilitated the implementation of team care.

Future research efforts should carefully examine the organizational resources invested in implementing team care across practice sizes and how supplementary PCMH payments enabled the recipient practices to enhance patient-centered care. ${ }^{2}$ Payers would want to know whether the money is best spent on supporting PCMH at a certain level or on paying for team care directly. At present, this study provides valuable lessons from the frontline on how successful PCMHs have overcome challenges to successfully develop and sustain a teamwork approach.

Conflict of Interest: The author has no conflict of interest with regard to the material in this article.

Corresponding Author: Ming Tai-Seale, PhD, MPH; Sutter Health Palo Alto Medical Foundation Research Institute, Palo Alto, CA 94301, USA (e-mail: Tai-sealeM@pamfri.org).

\section{REFERENCES}

1. O'Malley AS, Gourevitch R, Draper K, Bond A, Tirodkar MA. Overcoming challenges to teamwork in patient-centered medical homes: a qualitative study. J Gen Intern Med. 2014. doi:10.1007/s11606-014-3065-9.

2. Dohan D, McCuistion M, Frosch D, Hung D, Tai-Seale M. Recognition as a patient centered medical home: fundamental or incidental? Ann Fam Med. 2013;11(Suppl 1):S14-8.

Published online December 2, 2014 